\title{
Torsion of an epiploic appendage of the vermiform appendix
}

\author{
Yuri N Shiryajev, M.D., Anna V Glebova, M.D. \\ Department of Faculty Surgery named after Professor A.A. Rusanov, Saint-Petersburg State Pediatric Medical Academy, \\ Sixth Department of Surgery, Mariinsky Hospital, Saint-Petersburg, Russian Federation
}

We have read with great interest the paper by M.B. Aslam \& N. Hasan ${ }^{[1]}$ published in Turkish Journal of Trauma \& Emergency Surgery. They presented a very rare case of acute appendagitis caused by torsion of the epiploic appendage attached to the vermiform appendix. The authors reported: "To the best of our knowledge, no case of epiploica appendagitis or infarcted appendix epiploica in the vermiform appendix has been published previously".

According to our own literature review, this statement is false. Although appendiceal appendagitis is a very rare type of appendagitis, such cases have been published previously. It seems that the first one was reported by P. Klingenstein ${ }^{[2]}$ in 1924: "Operation revealed a completely gangrenous appendix vermiformis with a twisted epiploic appendage adherent and surrounding the perforating viscus". However, it is not considered as primary appendagitis, because necrotic changes of the appendage are secondary to appendicitis rather than torsion-related. On the contrary, H.J. Hambury ${ }^{[3]}$ described a true case of torsed epiploic appendage of the vermiform appendix, which mimicked acute appendicitis. In the photo presented in the article, the necrotized epiploic appendage is clearly visible on the background of the normal appendix. A similar clinical case report was published by V.V. Ornatsky. ${ }^{[4]}$ G.H. Colt ${ }^{[5]}$ operated on a female patient who complained of periodical pain in the left iliac fossa, nausea, and constipation. In the abdominal revision, two torsed epiploic appendages were found: one of the sigmoid colon and the other was close to the appendiceal tip; sigmoid appendage excision and appendectomy were performed by the author.

According to the data in the literature and clinical reports of the Mayo Clinic, T.E. Lynn et al. ${ }^{[6]}$ states that appendiceal appendagitis is rare in surgical practice - it accounts for only $3 \%$ of all appendagitis cases. This is a classical work on the sub-

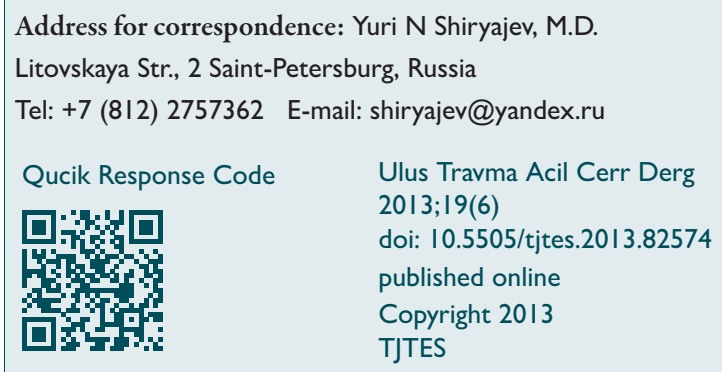

ject; its authors were the first to use the term "appendagitis", now widespread in English medical literature.

In what is probably the largest series of appendiceal appendagitis cases, presented in 2006 by I.M. Abdulzhavadov ${ }^{[7]}$ from Russia, an expert in the diagnosis and treatment of appendagitis (see the author's publication list, e.g., in PubMed), 14 observations were sampled. All patients underwent surgical treatment. Diagnostic laparoscopy was performed in four cases (correct diagnosis was made in two); there were 12 open surgeries that used McBurney's approach for suspected acute appendicitis.

The preferred surgical treatment in acute appendiceal appendagitis is appendectomy. It was found in the literature review that all patients presenting with the condition underwent this kind of treatment. In our opinion, if the diagnosis was confirmed laparoscopically, it seems unnecessary to remove the entire vermiform appendix. It is sufficient to make a laparoscopic excision of the torsed appendage. Similar surgical tactics, involving isolated laparoscopic excision of an epiploic appendage without incidental appendectomy, are sometimes used in torsion of the caecal epiploic appendage. [8,9] There are no published cases of such surgeries performed for acute appendiceal epiploic appendagitis in the literature.

Conflict of interest: None declared.

\section{REFERENCES}

1. Aslam MB, Hasan N. Torsion of an appendix epiploica present at the vermiform appendix: a rare cause of acute abdomen. Ulus Travma Acil Cerrahi Derg 2009;15:509-10.

2. Klingenstein P. Some phases of the pathology of the appendices epiploicae with a report of four cases and a review of the literature. Surg Gynecol Obstet 1924;38;376-82.

3. Hambury HJ. Torsion of an appendix epiploica of the vermiform appendix. Br J Surg 1952;40:176-7.

4. Ornatsky VV. Torsion of an appendix epiploica of the vermiform appendix. Khirurgiia (Mosk) 1957;(suppl);38.

5. Colt GH. Three cases of torsion of an appendix epiploica of the sigmoid colon. Br J Surg 1932;19;508-10.

6. Dockerty MB, Lynn TE, Waugh JM. A clinicopathologic study of the epiploic appendages. Surg Gynecol Obstet 1956;103:423-33.

7. Abdulzhavadov IM. Torsion of the epiploic appendages of the vermiform appendix. Klin Khir 2006;3:62-3.

8. DuBose JJ, Jenkins DM, Quayle CM, Dress AL, Cotlar AM. Laparoscopic resection of infarcted appendices epiploicae of the colon. Curr Surg 2005;62:362-4.

9. Sand M, Bonhag G, Bechara FG, Sand D, Mann B. An inflamed necrotic appendix epiploicum with immediate contact to a non-inflamed appendix vermiformis: a case report. J Med Case Rep 2009;3:57. 